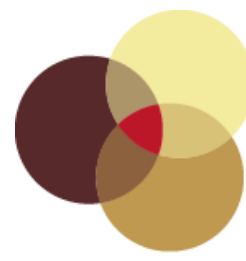

contennporaneity

Vol 7, No 1 (2018) ｜ＩSSN 2153-5914 (online) | DOI 10.5195/contemp/2018.264

http://contemporaneity.pitt.edu

\title{
Modern Art in the Arab World: Primary Documents
}

\author{
Anneka Lenssen, Sarah A. Rogers, and Nada M. \\ Shabout, eds.
}

Golnar Yarmohammad Touski

\section{Book Review}

Anneka Lenssen, Sarah A. Rogers, and Nada M. Shabout. Modern Art in the Arab World: Primary Documents. New York: The Museum of Modern Art, in association with Duke University Press, 2018. 464 pp.; 49 ills.; 51 b/w ills. Paperback, $\$ 40$ (1633450384, 9781633450387)

\section{About the Author}

Golnar Yarmohammad Touski is a doctoral student researching Iranian and Middle Eastern contemporary art at University of Pittsburgh's Department of History of Art and Architecture. As an artist, she studied painting and sculpture at University of Art (Daneshgah-e-Honar) in Tehran, Iran. Her research interests include postcolonial theory, modernism studies, uneven and combined development, relational aesthetics, mobility, borders, and geopolitics. 
Modern Art in the Arab World: Primary Documents Anneka Lenssen, Sarah A. Rogers, and Nada M. Shabout

\author{
Golnar Yarmohammad Touski
}

Among the most recent publications in MoMA's Primary Documents series, Modern Art in The Arab World is a timely arrival in the contemporary history of the Middle East and North Africa. With these 125 documents, the collection offers an unprecedented anthology of source material on modern art in the Arab world. The archive represents twelve Arabspeaking nation-states across the region as well as their Algerian, Egyptian, Iraqi, and Palestinian diasporas. In their socialist reading of postcolonial discourses, Anneka Lenssen, Sarah A. Rogers, and Nada M. Shabout trace the effects of global, artistic transformations in the Middle East, such as the emergence of national institutions and international art venues and their associated events in the Arab world. The editors mark a period of modernization in the region from 1882 to 1987 . The year 1987 marks a turning point of political transformation in the Middle East and a global shift to a "non-linear and coeval" order when academic tropes and art institutions emerged and were subsequently dismantled by avant-garde movements.

Documents included in the collection are predominantly translations of Arabic texts, but the editors carefully compare other regional, diasporic, and colonial languages against their sociocultural context and time frame. The texts range from artists' articles and diary entries, journal contributions, exhibition guest book entries, encyclopedia entries, manifestos, and letters, to national and international biennials documentation. Chronological ordering of texts is uniform format for MoMA's Primary Documents series, however the book does not include a consecutive connection among the disparate texts. In lieu of a timeline or map of political events, the editors organize the content around various thematic, pedagogical medium- and document-based constellations. For example, the titles "The Importance of Art," "Sculpture and The Public in Egypt," "Arab Romantics," and "Materials for a New Algerian Art" emphasize the importance of document-as-point-of-departure. As such, despite its chronological ordering, the book resists a comprehensive view and allows for an art historical reading salient to modernity's contradictions and flux. The editors chronicle a fluctuant history of artistic discourse and sociopolitical struggle that seeks to replace a more stylistically formal approach, the latter of which is often the conventional practice of writing about modern and contemporary art from the Middle East.

Due to the field's source documents' rare and scattered availability in English-language collections, the acts of collection and translation are necessary and overdue. However, the book goes beyond mere archival compilation as the texts and images scaffold a deterritorialized conception of modernity in the Arab world and speak to an existing trajectory of texts on modernism studies.

Fredrick Jameson famously critiqued the field of modernist studies for its offering "a modernity for everyone," whereby every nation-state was thought to inevitably catch up with the Euro-American notion of modernity. ${ }^{1}$ The editors address this misperception from the outset. To sidestep subjugating the Arab world to North Atlantic modernity, the book avoids an essentially geographical and hierarchal narrative both in terms of structure and content. They argue that "as artists, critics, and groups featured here went about formulating models for a responsible and flexible modernism, the Arab identity was often thought of as a frame in which to consolidate creative energies without subsuming all differences." They then assert that "to engage this writing about modern art, ideas and things, and events is to consider the deterritorialized aspects of historic modernism, and not a separate tradition or alterative modernism" (20). Therefore, modernism finds broader implications beyond formalistic

\footnotetext{
${ }^{1}$ Fredric Jameson, A Singular Modernity (London: Verso, 2012).
} 
modernism and is defined as Arab unity and resistance, post coloniality, globality, and progress.

In the introduction, Ussama Makdisi best articulates the forces of modernism, laying out a brief history of the formation of nation-states in the region vis-à-vis ideas of globality and progress. Here, he invokes historian Albert Hourani's reflection, "the tragedy of Arab history is that it was caught between an indigenous desire for self-determination and an incorrigible Western will to dominate the Arab world itself" (28). Hence, the book defines modernism in the space between these two forces. Such theoretical framework lends itself to a collection of some one hundred artworks-many of which are not widely known-as well as primary texts and focused, critical essays.

In the context of countries included in the book, translation is a performative and collective act of reimagining Arab polity. Paradoxically, the language of this imagined polity is not always Arabic. The Arab world introduced in the book, in effect, is a compendium of languages and ethnicities, many of which are absent from the constellation of texts; for example, those of Kurdish and Armenian accounts. Such absence is due to lack of archival documents, but it implies concepts of violence, conflict, and erasure. As such, non-Arab-speaking ethnicities and their lack of documentation are just as much part of a post-colonial discourse of belonging as the Arab speaking ethnicities documented in the book. The violence of erasure emerges elsewhere in writings of artists of the Arab world, such as the Algerian Lettrist Manifesto, which reads today as radical as it did upon its appearance in the third issue of the Internationale Lettriste (1952-1954). It opens with these chilling lines, "No human dies of hunger, thirst, or life. One can only die from renunciation" (163).

Translation here is a collective effort of a team of twenty translators working with scholars, who do so as a necessary act of making these materials available; but, more importantly, they work to translate the experience of reading them in the original context, complete with the discourses and challenges they posed. Modern Art in The Arab World provides not only a substantial archive, but also a liminal space of textual fluidity to revisit modernity outside of its North Atlantic core.

(cc) BY New articles in this journal are licensed under a Creative Commons Attribution 4.0 United States License.

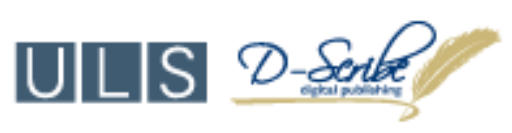

This journal is operated by the University Library System of the University of Pittsburgh as part of its D-Scribe Digital Publishing Program, and is co-sponsored by the University of Pittsburgh Press. 